\title{
Acoustic Emission Behavior on Fatigue Crack Characterization of Plasma Sprayed Hydroxyapatite Coated Layers
}

\author{
oTeerawat Laonapakul ${ }^{1, a}$, Yuichi Otsuka ${ }^{2, b}$ and Yoshiharu Mutoh ${ }^{3, c}$ \\ 'Dept. of Materials Science, Nagaoka University of Technology, Nagaoka-shi, Niigata, 940-2188, Japan \\ ${ }^{2}$ Dept. of System Safety, Nagaoka University of Technology, Nagaoka-shi, Niigata, 940-2188, Japan \\ ${ }^{3}$ Dept. of System Safety, Nagaoka University of Technology, Nagaoka-shi, Niigata, 940-2188, Japan

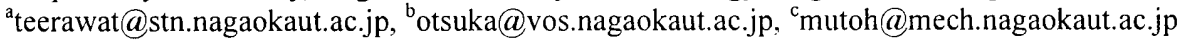

Keywords: Hydroxyapatite, Plasma spray coating, Fatigue, Acoustic emission

\begin{abstract}
In order to improve the adhesive strength of Hydroxyapatite (HAp) coating, the grid-blasting with $\mathrm{Al}_{2} \mathrm{O}_{3}$ powders and subsequently wet-blasting by $\mathrm{HAp} / \mathrm{Ti}$ mixed powders were applied on $\mathrm{Cp}-\mathrm{Ti}$ substrate. Two-layers of coating composed of $\mathrm{HAp} / \mathrm{Ti}$ bond coat and HAp top coat were deposited by plasma spraying. HAp-coated specimen could survive up to $10^{7}$ cycles, without spallation of HAp coating at the stress amplitude of $120 \mathrm{MPa}$ under four point bending fatigue test. In order to clarify mechanical failure behavior of the coatings and $\mathrm{Ti}$ substrate, acoustic emission (AE) signals during an entire fatigue process were observed. Relationship between $\mathrm{AE}$ and crack growth behaviors of coated specimens was evaluated to predict the fatigue lives of coating layers. HAp top coat with HAp/Ti bond coat show high adhesive strength where most of damages occurred at the final stage of fatigue life.
\end{abstract}

\section{INTRODUCTION}

To improve bioactivity, Ti and its alloys often coated with Hydroxyapatite (HAp) have been widely used in orthopaedic and dental applications. In this case, the biocompatibility of implant materials is assured by HAp, while the mechanical properties are reinforced by the metal substrate. In previous work (1), grit blasting and wet blasting with HAp/Ti mixed powders and deposition of a HAp/Ti bond coat between HAp top coat and $\mathrm{Ti}$ substrate was developed. Application of mixed $\mathrm{HAp} / \mathrm{Ti}$ bond coating could provide high strength of HAp top coat under tension-tension and compression-compression fatigue tests. In this study, the fatigue behavior of plasma sprayed HAp top coat with $\mathrm{HAp} / \mathrm{Ti}$ bond coat layers on $\mathrm{Cp}-\mathrm{Ti}$ substrate was investigated by four point bending condition. During the tests, $\mathrm{AE}$ behavior was monitored to discuss the damage process. Scanning electron microscope (SEM) observation and digital microscope were also carried out to reveal the morphologies of damage and to correlate the degree of damages in the coated specimen with the AE signals. Relationship between $\mathrm{AE}$ and crack growth behaviors of coated specimens was evaluated and used to predict the fatigue lives of HAp coated layers.

\section{EXPERIMENTAL PROCEDURES}

A rectangular shape of commercially pure titanium (Cp-Ti) grade 4 machined with size of $10 \times 50 \times 3 \mathrm{~mm}^{3}$ is used as substrate materials and then were grit-blasted by $\mathrm{Al}_{2} \mathrm{O}_{3}$ powders with 700 $\mu \mathrm{m}$ in average particle size. The blasted substrates were then blasted again by de-agglomerated HAp/Ti mixed powders $(3: 2$ volume ratios) of $100 \mathrm{ml}$ fed into $400 \mathrm{ml}$ distilled water with a wet blasting machine in order to generate a thin layer composed of $\mathrm{HAp} / \mathrm{Ti}$ on the surfaces of substrates and to improve an appropriate surface roughness for HAp plasma spray coating. A plasma spray coating was conducted using a commercial plasma spray machine operated at $36 \mathrm{kVA}(60 \mathrm{~V}, 600 \mathrm{~A})$ with a spraying distance of $30 \mathrm{~cm}$ under shield flow of Argon gas. The two-layers of coating composed of HAp top coat with HAp/Ti bond coat were deposited on wet blasted $\mathrm{Cp}$-Ti specimen with an average coating thickness of $50 \mu \mathrm{m}$ and $100 \mu \mathrm{m}$ respectively. Fatigue tests under four point bending with $20 \mathrm{~mm}$ inner span and $40 \mathrm{~mm}$ outer span by using sinusoidal wave form with a stress ratio, $\mathrm{R}=0.1$ and a frequency of $20 \mathrm{~Hz}$ were conducted in the controlled room at $23^{\circ} \mathrm{C}$ and $55 \%$ relative humidity. In order to clarify fatigue failure behavior and to predict the fatigue life of the coating layers, $\mathrm{AE}$ signals during the entire fatigue process were observed on both and single sides coating specimens. AE system (AE9922 combined with AS-712) with a gain value of $30 \mathrm{~dB}$ and a threshold value of $0.65 \mathrm{~V}$ was used to monitor the $\mathrm{AE}$ signal throughout the fatigue tests. SEM and digital microscope observation was also conducted to observe damage processes of the HAp coated specimens to identify the correlation between $\mathrm{AE}$ signal and damage morphology. The relationship between AE signal, average crack propagation length and number of fatigue cycles of coatings were used for the fatigue life prediction of HAp top coat and $\mathrm{HAp} / \mathrm{Ti}$ bond coat specimen.

\section{RESULTS AND DISCUSSIONS}

From the cross-sectional observations of as-sprayed specimen, it is clearly seen that the coated layers were tightly attached to the Ti substrate and also to the bond coat layer. S-N curves obtained almost coincide for as-wet blast $\mathrm{Cp}-\mathrm{Ti}$ and $\mathrm{HAp}$ coated specimens in Fig. 1. As-wet blasted and HAp coated specimens could survive up to $10^{7}$ cycles without delamination and spallation of HAp coating at the stress amplitude of $120 \mathrm{MPa}$. The examples of $\mathrm{AE}$ signals, $\mathrm{AE}$ peak amplitude, during the fatigue test under a stress amplitude of $220 \mathrm{MPa}$ are shown in Fig. 2. The AE signals under other stress amplitude conditions indicated similar tendency to Fig. 2. AE signals of as-wet blast specimens were mainly detected in the early and final stage and hardly detected in the intermediate stage of fatigue life. These signals may correspond to fatigue behaviors of $\mathrm{Cp}-\mathrm{Ti}$ which may be cause from dislocation movements, the plastic deformation and the crack propagation of $\mathrm{Cp}-\mathrm{Ti}$.

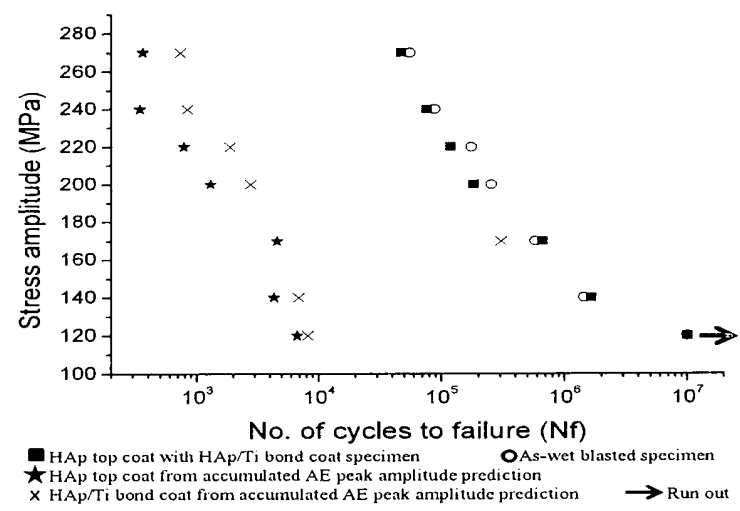

Fig. 1 S-N curves for as-wet blast Cp-Ti, HAp coated specimens, HAp top coat and HAp/Ti bond coat prediction 


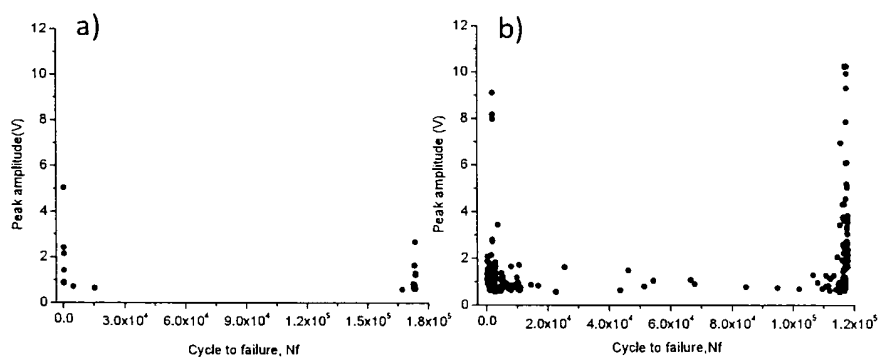

Fig.2 AE peak amplitude during the fatigue test under stress amplitude of $220 \mathrm{MPa}$ for as-wet blast $\mathrm{Cp}$-Ti (a) and HAp coated specimens (b)
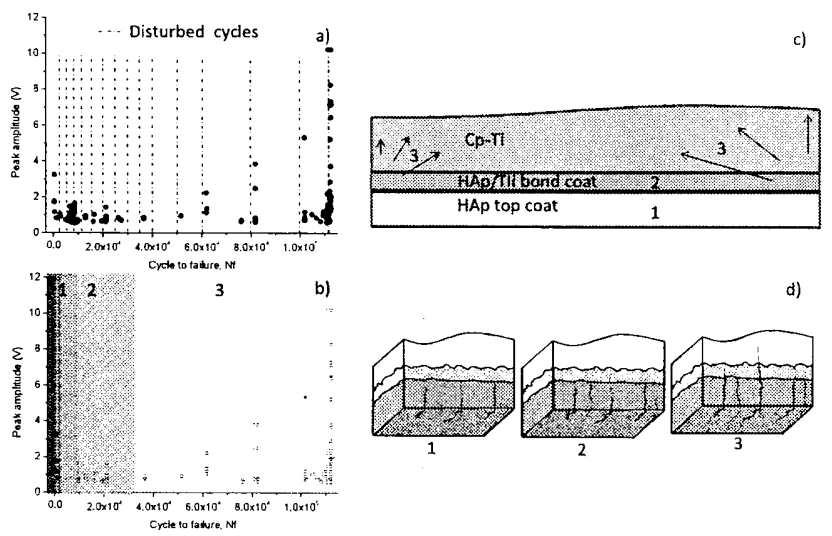

Fig.3 The relation between fatigue behaviors of HAp coated specimen and $\mathrm{AE}$ signals during fatigue test subjected to tension loading

In HAp coated specimens, dense and high values of $\mathrm{AE}$ signals were mainly detected in the beginning and last stage of fatigue test and occasionally detected during the middle stage of fatigue life. AE signals generated from HAp coated specimens are denser and higher than those of as-wet blasted specimens, which may correspond to the formations of crack and the failure of coating layers during the beginning and last stages respectively while the AE signals during the intermediate stage may correspond to the propagation of crack in coating layers. As a former result (2), the fatigue life of HAp coated specimen under bending fatigue test is dominated by cracks from the tension side. Moreover, the delamination cracks in compressive side of coating obviously observed only at the final stage of fatigue tests and it is not affected their fatigue lives. In order to clarify the relation between AE signals and failure of coatings, a single side coating of HAp coated specimen was also conducted the fatigue test under stress amplitude of $220 \mathrm{MPa}$ with $\mathrm{AE}$ monitoring in both tension and compression loading directions. $\mathrm{AE}$ signals from single side coating in tension fatigue loading indicated a similar tendency to both sides of coating as shown in Fig.2 (b) whereas AE signals from compression fatigue loading were detected in the early and final stages and scarcely detected in the intermediate stage of fatigue life.

In order to investigate fatigue life of HAp top coat and $\mathrm{HAp} / \mathrm{Ti}$ bond coat, the relationship between $\mathrm{AE}$ signals and fatigue damage in coating layers subjected to tension loading was evaluated. In-situ observation of the specimen during the fatigue test with $\mathrm{AE}$ measurement was carried out. A digital microscope (VHX-1000) was placed in front of the edge of the specimen which was polished until $1 \mu \mathrm{m}$ of diamond paste. Average crack propagation length in coating layers was measured between the inner span of four point bending during each interrupted fatigue cycles. AE signals from interrupted fatigue test in Fig. 3, (a) reveals the similar tendency with the continuous test which was shown in Fig 2 (b). From the observation, it could be noticed that some cracks completely propagated through HAp top coat after 3,000 cycles and then most of cracks reached HAp/Ti bond coat layer after 9,000 cycles of interrupted test at the same time some

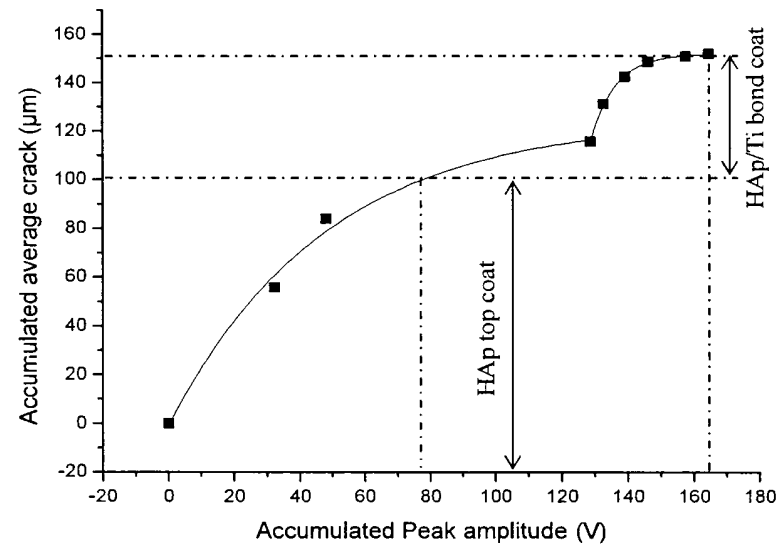

Fig 4 The relation between accumulated AE peak amplitude and accumulated average crack in HAp coating layers

cracks had already propagated into bond coat layer. Most of cracks reached $\mathrm{Ti}$ after 30,000 cycles thereafter cracks initiated and propagated into Ti substrate.

The relation between fatigue failure behaviors of HAp coated specimen and AE signal can be summarized by divided into three stages. During first and second stage, micro-cracks occurred in HAp top coat and HAp/Ti bond coat layers respectively and generated dense of $\mathrm{AE}$ signals as presented in Fig.3 (b). In third stage, crack initiated and propagated into $\mathrm{Ti}$ substrate starting from the edge corner of specimen without deflected to both interface layers which induced the macro-cracks in the coating layers in the final stage of its fatigue life. Therefore, The $\mathrm{AE}$ data referred to the damage crack in the coating layers during first and second stages were used to find the relation between crack propagation length and $\mathrm{AE}$ signal. The relation between accumulates AE signal and accumulated average crack length in HAp coating layers was plotted and fit in order to predict an average crack growth in coating layers as shown in Fig. 4. From the fit curves, it can be divided into two stages; first is the crack propagation in HAp top coat from $0 \sim 100 \mu \mathrm{m}$ and second is the crack propagation in HAp/Ti bond coat from $\sim 100 \sim 150 \mu \mathrm{m}$.

In order to predict fatigue life of coating layers, it is noted that the influent of AE signals from coating layers in compression side is possible to comprise. The values of $\mathrm{AE}$ signal accumulation after average crack propagated through HAp top coat and HAp/Ti bond coat calculated from the fit curves in Fig 4 were used to predict fatigue life of coating layers. The fatigue prediction in Fig. 1 presents very short fatigue life may due to the inclusion of $\mathrm{AE}$ signals from compression side of both side coating specimen which might be generated during the early stage of fatigue test.

\section{CONCLUSION}

Base on the in-situ observation and experimentally determined correlations between average crack propagation length in HAp top coat and HAp/Ti bond coat layers, AE signals and numbers of fatigue cycles, $\mathrm{AE}$ signal accumulation methods have been developed for estimating fatigue life of coating layers. HAp top coat and $\mathrm{HAp} / \mathrm{Ti}$ bond coat presented very short fatigue life compared to the $\mathrm{Ti}$ substrate. The inclusion of $\mathrm{AE}$ signals from compression side of both side coating specimen which might be generated at the area of upper support pins may be caused of the shorten fatigue life prediction from accumulation of $\mathrm{AE}$ signals. However, HAp top coat with $\mathrm{HAp} / \mathrm{Ti}$ bond coat show high adhesive strength where the delamination and the spallation of the coating layers was not observed until the final stage of fatigue life.

\section{REFERENCES}

1. Rakngarm A. and Mutoh Y., J. of the Mechanical Behavior of Biomedical Materials, Vol. 2 (2009), p. 444-453

2. Laonapakul T., Otsuka Y. and Mutoh Y., Key Engineering Materials, Vol. $452-453$, p. $857-860$ 